\title{
Brain damage and neurological outcome after open-heart surgery
}

\author{
K A SOTA N I EM I \\ From the Department of Neurology, University of Oulu, Oulu, Finland
}

S U M M A R Y Cerebral damage remains a major hazard of open-heart surgery. A one-year follow-up investigation of 100 consecutive patients who underwent open-heart operation for valve replacement revealed an incidence of postoperative cerebral disorders of $37 \%$. The occurrence of brain damage was clearly related to the presence of a history of previous neurological diseases, to operative hypoxia, and to unexpected events during operation, but long perfusion time proved to be the most significant risk factor. In contrast to previous findings, age and moderate operative hypotension proved unimportant. The abnormalities tended to resolve rapidly but, one year after operation seven patients still displayed residual signs. An interesting interhemispheric difference in susceptibility to damage was evident, the clinical signs indicating lesions of the right hemisphere in $71 \%$ of the damaged cases.

The nature of both preoperative and postoperative signs and symptoms, the determinants of brain damage and the significance of the observed disparity between the hemispheres are discussed. The continuous occurrence of brain damage obliges us to develop preventive measures more efficient than those now available.

Cerebral disorders related to cardiac surgery still cccur despite recent advances in surgical technique and extracorporeal circulation devices, these methods being far from perfect. ${ }^{1-3}$ With the ever-increasing number of applications of openheart procedures, there is a continuing need to recognise the potential threat of brain damage and to consider the factors which determine the outcome.

The reported incidence of cerebral damage after open-heart surgery varies widely. In prospective investigations incidences of $5 \%$ to $53 \%$ have been reported. ${ }^{24-7}$ In retrospective studies the incidence has usually been smaller: $19 \cdot 2 \%$ in a study of 417 patients $^{8}$ and $7.4 \%$ in a more recent study in 538 patients. ${ }^{1}$ By contrast, in an earlier investigation of 245 patients no obvious neurological disorders were found. ${ }^{9}$ The results are, however, not exactly comparable with each other because of differences in patients' age groups and cardiological diagnoses, in performed

Address for reprint requests: Dr Kyösti Sotaniemi, MD, Department of Neurology, University of Oulu, 90220 Oulu 22, Finland.

Accepted 7 August 1979 operative procedures, and, particularly, in the criteria of neurological evaluation: furthermore, the evaluation has not always been carried out by a neurologist.

The complications detected have been found to affect all levels of the nervous system. Hemispheral damage, resulting in various forms of motor and sensory defects or cognitive and intellectual impairment or psychiatric disorders, cranial nerve disturbances, and cerebellar or brain stem lesions are among the abnormalities most often reported. ${ }^{5610}$ Peripheral neuropathy has also been reported ${ }^{11}{ }^{12}$ as well as involvement of the brachial plexus. ${ }^{13}$

The causes and mechanisms of brain damage have been thoroughly discussed in several reports. $^{13681415}$ Microembolisation and inadequate cerebral perfusion seem to be regarded as the most probable mechanisms. Microembolisation may originate from the heart or from the extracorporeal circuit. ${ }^{16171819}$ The composition of emboli has been recognised to be varied: air, fat, antifoam particles, fragments of valvular debris, aggregates of platelets or leucocytes or denatured blood proteins. ${ }^{782021}$ Gaseous microembolism 
originating from the pump has been verified by ultrasonic methods ${ }^{22}$ and it has been shown to be reduced by microfiltration. ${ }^{23}$ Negative pressure conditions in the circuit supposedly assist in generating gaseous microemboli. ${ }^{17}$ Differences between the types of oxygenators seem to have been observed by some, ${ }^{219}$ but findings have not always been consistent with one another.

Cerebral perfusion inadequacy may be caused by hypothermia, ${ }^{24}$ hypoxia and hypotension ${ }^{68}$ or even by obstruction of the circulation due to malposition of the intravascular cannulae. ${ }^{25}$

Brain metabolic rate has been shown to fall during cardiopulmonary bypass both in clinical ${ }^{1526}$ and in anima ${ }^{1827}$ studies. There have also been reports of significant and not immediately reversible depression of cerebral blood flow and metabolism when associated with even short periods of bypass and supposedly caused by microembolisation. ${ }^{18}$ On the other hand, fall of metabolic rate thought to be due to decreased oxygen availability caused by haemodilution or loss of pulsatile pressure has been described. ${ }^{26}$

This study, part of a larger research programme investigating the effects of cardiac surgery on the central nervous system, was initiated to study the determinants and clinical characteristics of neurological complications related both to severe valvular disease and to open-heart surgery.

\section{Patients and methods}

One hundred consecutive patients admitted for valvular replacement surgery were examined during a period of over two years from May 1975. The sample comprised 37 women and 63 men whose ages ranged fnom 15 to 64 years at operation, mean age 44 years. The aortic valve was replaced (AVR) in 72 cases, the mitral valve (MVR) in 21, and both the valves (AVR + MVR) in seven. The cardiological diagnoses (table 1) were determined clinically and confirmed by a preoperative cardiac catheterisation in all of the

Table 1 Main cardiological diagnoses and operative procedures

\begin{tabular}{lr}
\hline Diagnosis and procedures & $\begin{array}{c}\text { No of } \\
\text { patients }\end{array}$ \\
\hline Aortic valve insufficiency (A1) & 26 \\
Aortic valve stenosis (AS) & 22 \\
AI + AS & 24 \\
Mitral valve insufficiency (MI) & 8 \\
Mitral valve stenosis (MS) & 13 \\
Combined aortic and mitral disease & 7 \\
\hline Aortic valve replacement (AVR) & 72 \\
Mitral valve replacement (MVR) & 21 \\
AVR + MVR & 7 \\
\hline
\end{tabular}

patients.

In most cases (91) a Björk-Shiley prosthesis was used and a Hall-Kaster model in the remainder. Cardiopulmonary bypass was carried through in moderate hypothermia, lowering the oesophageal temperature to $30-32^{\circ} \mathrm{C}$. During bypass mean arterial pressure was recorded at fiveminute intervals and blood gases were analysed at given periods. Preoperative bleeding was estimated to the accuracy of $50 \mathrm{ml}$. The duration of perfusion was registered in minutes. The degree of valvular calcification was classified as absent, moderate, or heavy. The methods of premedication, anaesthesia, postoperative care and controls, and any eventual dissimilarities in these measures were registered. Practice was, however, virtually uniform with no essential alterations during the period under survey. Cardiopulmonary bypass was carried out with the aid of the RyggKyvsgard bubble oxygenator in 90 cases and the Travenol TMO membrane oxygenator in 10 patients. Moderate haemodilution technique was used in all cases and the oxygenator was primed with a mixture of blood, gelatine, and Ringer's solution. Non-pulsatile flow was used in all patients.

Neurological evaluation Preoperative neurological evaluation consisted of two examinations which were always performed on the fifth and the second day before surgery. Postoperatively the first scheduled examination was carried out on the 10th day, up to which time the patient had already spent a few days on a regular surgical ward. The next contact took place at the outpatient clinic two months after operation and the following examinations were performed every three months up to one year. The follow-up period was therefore one year and included five neurological evaluations at fixed intervals. Every examination consisted of a complete clinical neurological investigation, a standardised interview to ascertain neurological symptoms, and an evaluation of mental status, awareness, orientation, speech, praxis, and memory. Owing to the fact that the patients were investigated uniformly according to the established protocol and that the evaluation was always made by the same person, all the observable abnormalities and not only severe or obvious disorders could be registered. Signs present before operation were not recorded as new findings later; abnormalities which could be interpreted as a part of a larger entity were not listed separately.

In addition to the clinical evaluation described above, all of the patients underwent an electroencephalographic follow-up, and a detailed neuro- 
Table 2 Preoperative and postoperative history and symptoms. Results are numbers of patients

\begin{tabular}{llrr}
\hline History & \multicolumn{2}{c}{$\begin{array}{l}\text { Before } \\
\text { operation }\end{array}$} & \multicolumn{2}{c}{ After operation } \\
\cline { 4 - 4 } & & & Early \\
\hline $\begin{array}{l}\text { Major CVA: } \\
\quad \text { subarachnoid haemorrhage }\end{array}$ & 1 & 0 & 0 \\
$\quad$ cerebral thrombosis & & & \\
$\quad$ or embolism: & 4 & 0 & 2 \\
$\quad$ spontaneous & & & \\
$\quad$ after a previous & 3 & 0 & 1 \\
$\quad$ cardiac operation & 5 & 4 & 8 \\
TIA & 12 & 5 & 12 \\
Migraine & 11 & 29 & 1 \\
Other forms of headache & 11 & 2 & 2 \\
Vertigo, dizziness & 9 & 23 & 7 \\
Syncope & 3 & 7 & 3 \\
Sleep disturbances & 4 & & \\
Neurovegetative disorders & 2 & & \\
& & & \\
\hline
\end{tabular}

psychological and psychiatric assessment was performed in most cases according to a larger research programme. Student's T-test was used.

\section{Results}

Preoperative history Neurological complaints were the most common: 55 patients reported at least one kind of symptom during the last year. Headaches, dizziness, and vertigo were among the most common (table 2). A history of previous cerebrovascular disorders was reported in 14 patients $(14 \%)$. Five patients had suffered from at least two episodes classifiable as transient ischaemic attacks (TIA), manifesting as amaurosis fugax in two cases, aphasia in two, and right side hemiparesis and aphasia in one. Nine patients had sustained a major cerebrovascular accident (CVA): five had survived a stroke associated with hemiparesis or visual field defects and cognitive impairment; in three cases the accident had followed a previous cardiac operation; and one
Table 3 Preoperative neurological abnormalities

\begin{tabular}{lc}
\hline & $\begin{array}{c}\text { No of } \\
\text { patients }\end{array}$ \\
\hline Right sided hemiparesis & 2 \\
Left sided hemiparesis & 3 \\
Crossed hemiparesis & 1 \\
Left eye blindness and slight aphasia & 1 \\
Unilaterial dysmetria, nystagmus & 1 \\
Partial oculomotor lesion & 1 \\
Essential tremor & 1 \\
Anisocoria & 2 \\
Femoral neuropathy (iatrogenic, after cardiac catheterisation) & 2 \\
\hline
\end{tabular}

of the patients had had subarachnoid haemorrhage $(\mathrm{SAH})$ of inexplicable origin one year earlier.

Nine patients reported a tendency to syncopal attacks. These patients had aortic valve disease and the episodes of syncope had usually occurred repeatedly in connection with physical exercise.

Preoperative signs Neurological abnormalities were found in 13 patients $(13 \%)$; a few cases of known traumatic or infectious cause are not included. The findings are shown in table 3 . Residual signs of hemiparesis were found in six patients, one of whom had sustained cerebral damage in a previous heart operation: a history of spontaneous CVA was present in four patients, one of whom had survived SAH; two patients had signs indicating a brain-stem lesion.

On considering the signs that probably originated from the cerebral level, an interhemispheric difference was found to exist, the signs referring to the left hemisphere in $70 \%$ of those patients with a history of spontaneous cerebral vascular disorders.

Postoperative findings Ninety-six patients survived to be discharged-a mortality of $4 \%$. The clinical data and postmortem findings of the non-survivors are presented in table 4. Two

Table 4 Clinical data and postmortem findings of non-survivors

\begin{tabular}{|c|c|c|c|c|c|c|c|c|}
\hline $\begin{array}{l}\text { Patient } \\
\text { code }\end{array}$ & Sex & $\begin{array}{l}\text { Age } \\
(y r)\end{array}$ & $\begin{array}{l}\text { History of } \\
\text { preoperative } C V A\end{array}$ & $\begin{array}{l}\text { Operative } \\
\text { procedure }\end{array}$ & $\begin{array}{l}\text { Perfusion } \\
\text { time (min) }\end{array}$ & $\begin{array}{l}\text { Operative } \\
\text { disturbances }\end{array}$ & Neuropathological findings & $\begin{array}{l}\text { Time and } \\
\text { cause of death }\end{array}$ \\
\hline 5 & $\mathbf{M}$ & 51 & No & AVR & 335 & $\begin{array}{l}\text { Very heavy } \\
\text { valv. calcif. }\end{array}$ & $\begin{array}{l}\text { Multiple small cerebral infarcts } \\
\text { and petechial hemorrhages }\end{array}$ & $\begin{array}{l}\text { 4. postop. day } \\
\text { Brain damage. }\end{array}$ \\
\hline 31 & $\mathbf{M}$ & 64 & Yes & AVR & 182 & $\begin{array}{l}\text { Massive } \\
\text { bleeding }\end{array}$ & $\begin{array}{l}\text { Moderate arteriosclerosis. } \\
\text { Multiple infarcts particularly in } \\
\text { occipital areas, brain stem and } \\
\text { cerebellum }\end{array}$ & $\begin{array}{l}\text { 3. postop. day } \\
\text { Brain damage }\end{array}$ \\
\hline 22 & $\mathbf{F}$ & 47 & Yes & AVR & 148 & No & $\begin{array}{l}\text { Gross and histologic anatomy } \\
\text { normal }\end{array}$ & $\begin{array}{l}\text { 6. postop. day } \\
\text { Cardiac death. }\end{array}$ \\
\hline 84 & $\mathbf{F}$ & 51 & Yes & AVR & 104 & No & $\begin{array}{l}\text { Gross and histologic anatomy } \\
\text { normal }\end{array}$ & $\begin{array}{l}\text { 8. postop. day } \\
\text { Retroperitoneal } \\
\text { hemorrhage. }\end{array}$ \\
\hline 11 & $\mathbf{M}$ & 52 & No & MVR & 181 & No & $\begin{array}{l}\text { Brain not examined. (Liver: } \\
\text { massive necrosis) }\end{array}$ & $\begin{array}{l}\text { 3. months postop. } \\
\text { Liver necrosis }\end{array}$ \\
\hline 13 & $F$ & 49 & No & MVR & 122 & $\begin{array}{l}\text { Prolonged } \\
\text { hypotension }\end{array}$ & $\begin{array}{l}\text { No postmortem information } \\
\text { available }\end{array}$ & $\begin{array}{l}\text { 2. months postop. } \\
\text { Sudden death } \\
\text { (arrhythmia?) }\end{array}$ \\
\hline
\end{tabular}


Table 5 Major neurological complications after surgery

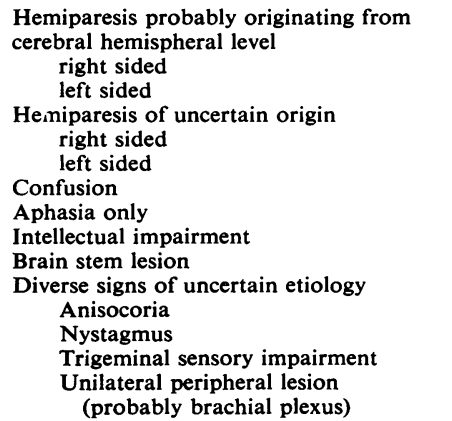

patients died within four days of surgery without gaining consciousness; both showed massive focal signs of brain damage. Two more patients died of evidently non-cerebral causes at the end of the first week, having got through the operation without manifest neurological complications. Two later deaths occurred within three months: in cne of the cases cardiac aetiology was suspected, the other patient dying of massive liver necrosis. Focal cerebral signs had been present in these two patients after surgery but they had recovered completely before the second postoperative examination.

The brains of the patients who died in the hospital were available for necropsy. In the cases of operative death marked brain damage was found to be the principal cause: multiple small haemorrhages and acute ichaemic neuronal damage was seen both in the cerebral hemispheres and in the brain stem and cerebellum. By contrast, no pathological findings could be seen in the brains of those two patients who died of evidently non-cerebral causes and who had not shown any neurological disorders.

Postoperatively, neurological abnormalities referring to central nervous system damage were detected in 37 patients $(37 \%)$. There were both focal and diffuse, single and multiple signs from which the most important are presented in table 5. Hemiparesis of various nature and severity was the most common major abnormality and was seen in 24 cases $(24 \%)$. It was usually motor and of slight degree, sensory impairment being present in about one fourth of the cases. A more severe hemiplegia was present in two cases. Hemiparesis was left sided in 17 cases out of 24 and in the great majority (22) of cases its origin was thought to be hemispheral, the spinal cord level being suspected in two cases.

The cerebral lesion contributing to the main clinical manifestation was considered to originate from the cerebral hemispheral level in $79 \%$, from the cerebellum or brain stem level in $16 \%$, and from the spinal cord level in $5 \%$.

It was evident that peripheral nervous tissue involvement was also rather frequent. Sensory or motor impairment of one or both upper extremities was found in 12 patients and the signs and symptoms were mostly those seen in ulnar nerve or lower brachial plexus lesions. In three cases there was both sensory and motor involvement, which caused moderate damage. In most cases partial lower plexus stretch injury was suspected.

Follow-up Follow-up according to the protocol could be carried out in $85 \%$ of the survivors in full but only for a period of up to eight months in the remaining cases, none of whom showed abnormal signs at the last examination.

Disability caused by neurological complications was usually relatively slight but some patients were handicapped. Hemiplegia alone in one case and accompanied with aphasia in another was severe enough to cause moderate disability as did the impairment of higher cerebral functions in four additional patients. The patients who had no clinical focal signs but were confused recovered totally. Brain-stem signs also disappeared totally within two months and caused no real disability at any time.

Generally the abnormalities tended to resolve rapidly which was well shown by the convalescence from hemiparesis: 13 of the 24 patients recovered totally within two months; four displayed residual signs five months after operation; and three showed residual signs eight months after operation.

After one year neurological abnormalities were still present in seven patients: residual hemiparesis was seen in two of them, two had not recovered totally from intellectual impairment, one was disabled by aphasia, and two patients had slight signs of unilateral brachial plexus involvement.

During follow-up two patients sustained CVAs. They had both suffered brain damage during operation resulting in left-sided hemiparesis; having recovered completely within a few weeks, both suffered a new CVA with the same kind of signs. None of the patients with a preoperative history of TIA developed more attacks, but one patient, not damaged at operation, suffered from a few TIA episodes shortly after surgery but not thereafter. The incidence of syncope decreased significantly, only one patient reporting a single event. 
Table 6 Prognostic values of preoperative neurologic history and signs

\begin{tabular}{lccc}
\hline History of sign & $\begin{array}{l}\text { Number of } \\
\text { cases }\end{array}$ & \multicolumn{2}{c}{$\begin{array}{l}\text { Postoperative brain } \\
\text { damage observed in }\end{array}$} \\
\hline CVA & & $N$ & $\%$ \\
TIA & 9 & 6 & 66.7 \\
Syncope & 5 & 2 & 40.0 \\
Migraine & 9 & 6 & 66.7 \\
Epilepsy & 12 & 5 & 41.7 \\
Previous heart operation & 3 & 2 & 66.7 \\
Hemiparesis & 12 & 5 & 41.7 \\
& 5 & 3 & 60.0 \\
\hline
\end{tabular}

Two patients developed psychomotor epileptic attacks which appeared about six months after the operation and were readily controlled by medication. They had both shown focal neurological signs postoperatively, probably caused by air embolism which had been suspected during operation. The postoperative symptoms are presented in table 2 .

\section{FACTORS RELATED TO CEREBRAL DAMAGE}

Several factors (such as age, sex, valvular disease and degree of calcification, presence of previous neurological diseases, pre- and peroperative medication, type of oxygenator, cardiac rhythm, duration of operation and perfusion time, operative hypotension, hypothermia, and hypoxia, type of prosthesis, unexpected events during surgery, blood loss) were recorded and analysed in relationship to the cerebral disorders. Among them the following deserve consideration:

(1) Age below 60 years proved to be unimportant. The incidence of brain damage in the different age groups is presented in table 7 . The mean age of the non-damaged patients was $43 \cdot 2 \pm 10 \cdot 5$ years and $44 \cdot 7 \pm 8 \cdot 2$ years in the damaged group, the difference being insignificant. The number of patients aged over 60 years was so small (2) that the statistical significance of their possible increased risk to damage remained doubtful.

(2) The presence of a preoperative history of CVA or tendency to syncopal attacks proved significant and almost doubled the risk of brain damage. On the other hand, patients who had reported TIAs seemed no more vulnerable than the average. The results are shown in table 6 .

(3) Duration of perfusion was the most important single determinant of brain damage. Brain damage was present in $19.5 \%$ of those who underwent perfusion for less than two hours compared with $51.9 \%$ of those with a longer perfusion time, the difference being highly significant $(p=0.0001$; tatle 8$)$. It is noteworthy that there were no significant differences between the ages of the patients in the various perfusion time

Table 7 Relationship between age, perfusion time and brain damage

\begin{tabular}{|c|c|c|c|c|c|c|c|}
\hline \multirow[t]{2}{*}{$\begin{array}{l}\text { Age group } \\
(y r)\end{array}$} & \multirow[t]{2}{*}{ Number of patients } & \multicolumn{2}{|c|}{$\begin{array}{l}\text { Postoperative brain } \\
\text { damage present in }\end{array}$} & \multirow[t]{2}{*}{ Perfusion time } & \multirow[t]{2}{*}{ Number of patients } & \multicolumn{2}{|c|}{$\begin{array}{l}\text { Postoperative brain } \\
\text { damage present in }\end{array}$} \\
\hline & & $\bar{N}$ & $\%$ & & & $N$ & $\%$ \\
\hline $15-19$ & 3 & 1 & 33.3 & $\begin{array}{l}<2 h \\
\geqslant 2 h\end{array}$ & $\begin{array}{l}2 \\
1\end{array}$ & $\begin{array}{l}0 \\
1\end{array}$ & $\begin{array}{c}0 \\
100.0\end{array}$ \\
\hline $20-29$ & 8 & 3 & 37.5 & $\begin{array}{l}<2 h \\
\geqslant 2 h\end{array}$ & $\begin{array}{l}2 \\
6\end{array}$ & $\begin{array}{l}0 \\
3\end{array}$ & $\begin{array}{c}0 \\
50.0\end{array}$ \\
\hline $30-39$ & 15 & 4 & 26.7 & $\begin{array}{l}<2 h \\
\geqslant 2 h\end{array}$ & $\begin{array}{l}9 \\
6\end{array}$ & $\begin{array}{l}1 \\
3\end{array}$ & $\begin{array}{l}11.1 \\
50.0\end{array}$ \\
\hline $40-49$ & 43 & 17 & 39.5 & $\begin{array}{l}<2 h \\
\geqslant 2 h\end{array}$ & $\begin{array}{l}23 \\
20\end{array}$ & $\begin{array}{r}7 \\
10\end{array}$ & $\begin{array}{l}30.4 \\
50.0\end{array}$ \\
\hline $50-59$ & 29 & 10 & 34.5 & $\begin{array}{l}<2 h \\
\geqslant 2 h\end{array}$ & $\begin{array}{l}10 \\
19\end{array}$ & $\begin{array}{l}1 \\
9\end{array}$ & $\begin{array}{l}10.0 \\
47.4\end{array}$ \\
\hline $60-69$ & 2 & 2 & 100.0 & $\begin{array}{l}<2 h \\
\geqslant 2 h\end{array}$ & $\overline{2}$ & $\overline{2}$ & $\overline{100.0}$ \\
\hline
\end{tabular}

Table 8 Perfusion time and incidence of brain damage

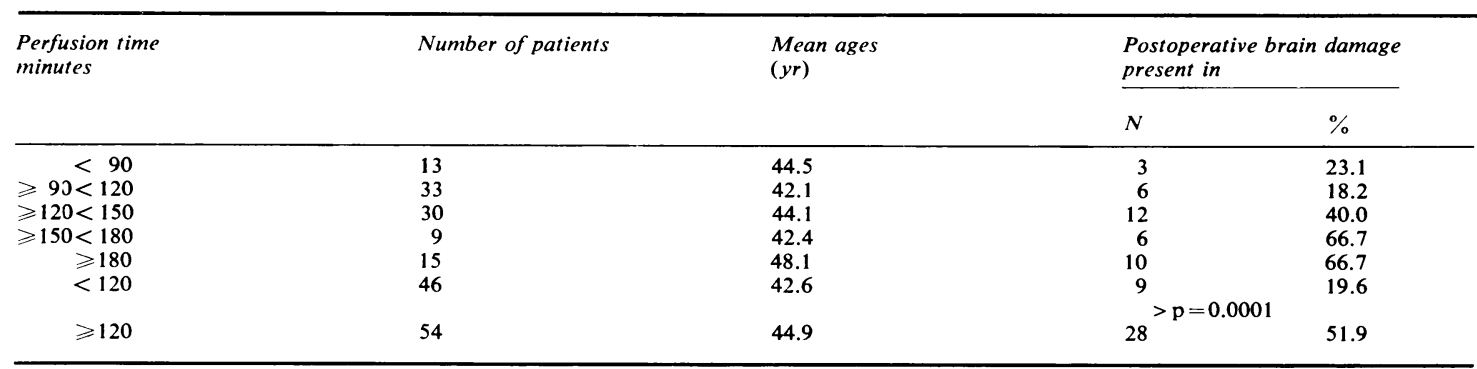


Table 9 Effect of hypotension on the occurrence of brain damage

\begin{tabular}{|c|c|c|c|c|}
\hline \multirow[t]{2}{*}{ Mean arterial pressure $\mathrm{mm} \mathrm{Hg}$} & \multirow[t]{2}{*}{ Duration of hypotension } & \multirow[t]{2}{*}{ Number of patients } & \multicolumn{2}{|c|}{ Brain damage observed in } \\
\hline & & & $N$ & $\%$ \\
\hline \multirow{4}{*}{$<60 \geqslant 50$} & $\leqslant 5$ & 11 & 4 & 36.3 \\
\hline & $>5 \leqslant 10$ & 5 & 3 & 60.0 \\
\hline & $>10 \leqslant 15$ & 6 & 3 & 50.0 \\
\hline & $>15$ & 11 & 3 & 34.1 \\
\hline \multirow[t]{4}{*}{$<50$} & $\leqslant 5$ & 21 & 7 & 33.3 \\
\hline & $>5 \leqslant 10$ & 10 & 4 & 40.0 \\
\hline & $>10 \leqslant 15$ & 7 & 3 & 42.9 \\
\hline & $>15$ & 3 & 1 & 33.3 \\
\hline
\end{tabular}

groups. Duration of perfusion was found to be important independent of age (table 7).

(4) Mean arterial pressure during perfusion seemed to be of minor importance and no significant correlation was found between either the degree or the duration of hypotension and brain damage (table 9). Mean arterial pressure of 50 $\mathrm{mm} \mathrm{Hg}$ or less was observed in 41 patients: mean time of such hypotension $( \pm \mathrm{SD}$ ) was $9 \cdot 04 \pm 5 \cdot 40$ $\mathrm{min}$ in the non-damage group and $9.62 \pm 5.19 \mathrm{~min}$ in the damaged patients, the difference being insignificant $(p=0 \cdot 38)$. It must be emphasised that there were a few occasions of sudden fall of pressure even to $40 \mathrm{~mm} \mathrm{Hg}$ without detectable complications. Furthermore, the incidence of cerebral damage among the 26 cases in which pressure never fell below $60 \mathrm{~mm} \mathrm{Hg}$ was $39 \cdot 1 \%$. Hypotension was not found more harmful in advanced age.

(5) The degree of valvular calcification appeared important only in cases where it was graded heavy: on such occasions disorders were found in $58.8 \%$. Where abundant fragmentation of the deposits had been reported the incidence of brain damage rose to $66.7 \%$.

(6) No significant difference was found between aortic and mitral operations, the incidence of complications being $36.1 \%$ and $33.3 \%$ respectively: but when both valves were deplaced the incidence rose to $57 \cdot 1 \%$.

(7) The amount of blood loss usually depended on the length of the operation, but profuse bleeding was seen to be accompanied with cerebral disorders regardless of the time factor. When bleeding was more than $2500 \mathrm{~m} 1$, complications were found in nine cases out of ten.

(8) Unexpected events during operation were often accompanied with brain damage. In four cases difficulties with the oxygenator were reported and low values of arterial oxygen pressure were measured (from 6.0 to $8.4 \mathrm{kPa}$ ), subsequent cerebral complications were present in all of them. The same was found in three cases with observed or highly suspected operative embolism.
(9) The role of the oxygenator type remains unsettled because of the small number of cases in which the membrane oxygenator was employed. It is noteworthy, however, that with the use of the membrane oxygenator cerebral damage was detected in only two patients out of ten; in five patients the duration was less than two hours and in cases of damage the duration was over 180 minutes.

\section{Discussion}

The observed incidence of central nervous system abnormalities after open-heart surgery was $37 \%$, being of the same magnitude as in earlier studies $^{5}$ but far more frequent than reported in more recent studies. ${ }^{12}$ The later investigations, however, differ markedly from the present study as the criteria for neurological evaluation are not comparable with each other; applying analogous criteria to this study would produce an incidence as low as $9 \%$. In our evaluation, neurological abnormalities were registered regardless of their severity and nature. The final aim of investigating this subject is to learn to recognise and minimise or even eliminate the factors that determine brain damage and this involves considering every single complication independent of its degree. In this investigaticn some of the minor complications may have been missed because of the timing of the first postoperative examination but, on the other hand, casual abnormalities related to anaesthesia and medication ${ }^{28}$ were probably avoided.

Operative and early postoperative mortality in this series was low (4\%). Necropsy information from only four cases is insufficient for neuropathological conclusions to be drawn, but the findings of severe cerebral damage seen in both of the operative deaths were in accordance with previous findings. ${ }^{169}$ The neuropathological observations have been thoroughly reviewed. ${ }^{14}$

The frequent involvement of cerebral functions reflects the imperfection of the cardiopulmonary bypass devices and the necessity for further 
efforts to develop and improve both the equipment and the operative procedures. Several crerating centres have carefully studied and practised preventive measures and reduced complications considerably, ${ }^{12}$ but complete elimination has not yet been achieved.

The factors most often put forward as responsible for brain damage are embolisation and inadequate cerebral perfusion. ${ }^{8}$ Among the variables most likely to increase the degree of risk advanced age, long duration of perfusion, low perfusion pressure, and the presence of a history of previous neurological diseases have proved to be the most important. ${ }^{5630}$ However no single factor has proved absolutely decisive alone ${ }^{14}$ and the roles of the determinants are somewhat controversial. In a retrospective study ${ }^{8}$ the possible cause of brain damage could be named in $40 \%$ of cccurrences: in this study it can be stated in 12 cases out of $37(32.4 \%)$ : hypoxia in five cases, massive bleeding, and technical difficulties in two cases and embolisation in three survivors and in two non-survivors.

The presence of a history of preoperative CVA seemed to correlate positively with the incidence of brain damage, which ocurred in $66.7 \%$ of cases, regardless of whether or not clinical signs could still be seen preoperatively. This supports the findings of Branthwaite ${ }^{8}$ but there are papers reporting prognostic values only if the clinical signs are still present. $^{58}$ On the other hand, previous cardiac operations, independent of neurological outcome, did not increase the risk, and the same was found to be true in cases with a history of transient ischaemic attacks. This leads to the conclusion that cerebrovascular diseases cannot be considered as a homogeneous entity for prognostic purposes in evaluating the neurological risks of extracorporeal circulation.

A history of syncopal attacks appeared disadvantageous, being associated with cerebral disorders in $66.7 \%$ of cases. The importance of tlackout spells has not been discussed in previous reports and the prognostic significance must be reassessed with more subjects but it is noteworthy that there existed another known factor possibly contributing to damage in only one of the cases (table 6).

The importance of age has been emphasised in several communications ${ }^{568}$ but could not be confirmed in this study as presented in table 7 . Some proof could be seen however in the unfavourable outcome of the two oldest patients (both aged 64) but both of them also had a long perfusion time (154 and $182 \mathrm{~min}$ ). In addition there was a trend increasing with advancing age to higher susceptibility to damage after only a short perfusion time (table 8). But if age were of major importance there should have been a particularly clear-out correlation between age and frequency of complications after long durations of perfusion and this could not be verified. There is no evidence of the increased harmfulness of hypotension with advancing age which provided further support for the minor value of age. The present results cannot be explained by any variables specially favourable to the older patient groups and disadvantageous to the younger groups (as for age and perfusion time, see table 8). It may be concluded that age itself is not a matter of importance but rather the state of the regulatory mechanisms of circulation.

Duration of perfusion proved the most significant of the operative variables directly verifying the cumulatively damaging character of cardiopulmonary bypass conditions. Perfusion time shorter than two hours was accompanied by cerebral disorders in $19.6 \%$ of cases in contrast to $51.9 \%$ after longer duration of bypass, the difference being highly significant $(p=0.0001)$. The same time limit has been found earlier ${ }^{58}$ and the definite benefits of short perfusion time policy have been well documented. ${ }^{210}$ In the present study, the significance is further accentuated by the relatively slight weight of other factors, such as hypotension and age. The final harmful causes related to cardiopulmonary bypass have not been definitely ascertained and cannot be solved by clinical investigations-for example, studies on microembolisation ${ }^{22}$ have shown that it does not necessarily cause any detectable damage. Until we have more detailed solutions the practical ccnclusion is to use as short a perfusion time as possible.

Information on the role of hypotension during bypass is controversial. Hypotension has been regarded as a major determinant of cerebral damage by some authors ${ }^{53031}$ and less important by others. ${ }^{248}$ Our results show indisputably that moderate hypotension alone is not a decisive determinant contributing to brain dysfunction.

During perfusion severe hypotension (below $40 \mathrm{~mm} \mathrm{Hg}$ ) could be effectively avoided but mean arterial pressure below $50 \mathrm{~mm} \mathrm{Hg}$ was recorded in more than one third of the patients and there were no significant differences between the damaged and non-damaged patient groups in the duration or degree of hypotension. There was no positive correlation between age and harmfulness of moderate hypotension and there were occasions when pressure fell suddenly to $40 \mathrm{~mm}$ $\mathrm{Hg}$ without detectable disorders. Cerebral cir- 
culation is known to be able to adopt to hypotension with a mean arterial pressure of $50 \mathrm{~mm}$ $\mathrm{Hg}^{32}{ }^{33}$ but our findings suggest that the critical limit is idiosyncratic and may be influenced by other coincidental factors. Our results lead to the conclusion that the factors of actual importance are first the causes of hypotension and second, the individual's abilities to tolerate the condition and to respond to it.

The observed interhemispheric difference in susceptibility to damage deserves consideration, particularly because it has not been reported before. Some references to similar results can be seen in previous studies ${ }^{5}$ but the matter has not been discussed. In this study, the preoperative signs and case histories referred to the left hemisphere in $70 \%$ of cases but, by contrast, the postoperative signs originated from the right hemisphere in $71 \%$. Hemiparesis, which was the most usual major complication, was left-sided in 16 of the 22 cases in which the origin could be localised to the cerebral level. These cases were analysed with special care in relation to preoperative, intraoperative, and postoperative variables but no explanation could be stated on clinical grounds to the disparity between right and left hemispheral involvement. All the patients were right-handed, no cervical vascular disease could be verified clinically, and no positional or technical cause favouring right side involvement could be determined. It is unlikely that emboli of any kind would prefer the right carotid artery to the left side or that a large group of patients would have similar vascular anomalies. The present knowledge of interhemispheral differences includes mainly neuropsychological information ${ }^{34}{ }^{35}$ and electroencephalographic findings ${ }^{36}{ }^{39}$, but knowledge of the conditions of microcirculation and metabolism as well as of their regulators is practically non-existent. Because the hemispheres are different from each other in dominance, neuropsychological functions, and electrical characteristics there may also be differences in maintaining normal functions under exceptional conditions and in tolerating damage. The mechanism of dissimiliarities remains unsettled on a clinical basis, but either the dominant and more specialised left hemisphere may be more resistant to harmful factors such as are present during cardiopulmonary bypass, or conversely there may be a direct cause damaging the right side alone, or perhaps the hemispheres are uniformly involved but the threshold in producing clinical manifestations is different for each hemisphere. An indirect involvement of this kind seems un- likely to be strong enough to lead to clinical signs in the undamaged hemisphere if there are no signs from the primarily affected hemisphere. However, there are reports of bilateral abnormalities in unilateral brain damage cause by microembolisation ${ }^{26}{ }^{38}$ and by irradiation. ${ }^{29}$ The interhemispheric difference observed by clinical neurological methods remains to be confirmed and its significance reassessed after evaluation of the results of electroencephalographic and psychometric tests, the analysis of which is already under way.

The final brain damaging effects of cardiopulmonary bypass are at least partly uncertain and because clinical methods are of limited value in explaining the basic events, investigations must be focused on the nerve cell level and on the regulators of its metabolism. Open-heart operations with cardiopulmonary bypass have proved to be a potent multifactorial hazard for all the levels of the nervous system and the advances thus far still seem inadequate.

\section{References}

1 Branthwaite MA. Prevention of Neurological damage during open-heart surgery. Thorax 1975; 30:258-61.

2 Åberg $T$, Kihlgren M. Cerebral protection during open-heart surgery. Thorax 1977; 32: 525-33.

3 Ross Russell RW, Bharucha N. The recognition and prevention of border zone cerebral ischaemia during cardiac surgery. $Q \mathrm{~J}$ Med, New Series 1978; 47:303-23.

4 Gilman S. Cerebral disorders after open-heart operations. $N$ Engl J Med 1965; 272:489-98.

5 Javid H, Tufo HM, Najafi H, Dye WS, Hunter JA, Julian OC. Neurologic abnormalities following open-heart surgery. $J$ Thorac Cardiov Surg 1969; 58:502-9.

6 Tufo HM, Ostfeld AM, Shekelle R. Central nervous system dysfunction following open-heart surgery. J Am Med Ass 1970; 212:1333-40.

7 Lee WH, Krumhaar D., Fonkalsrud EW, Schjeide OE, Maloney IV. Denaturation of plasma proteins as a cause of morbidity and death after intracardiac operations. Surg 1961; 50:29-39.

8 Branthwaite MA. Neurological damage related to open-heart surgery. Thorax 1972; 27:748-53.

9 Patrick RT, Kirklin JW, Theye RA. The effects of extracorporeal circulation on the brain. In: Allen JG, ed. Extracorporeal circulation. Springfield, Ill. Charles G Thomas 1958; 272.

10 Åberg T, Kihlgren M. Effect of open-heart surgery on intellectual function. Scand $J$ Cardiov Surg 1974; Suppl 15.

11 Walsh JC. Mononeuritis multiplex complicating 
the post-perfusion syndrome. Aust NZ J Med 1968; 17:327-30.

12 Keates JRW, Innocenti DM, Ross DN. Mononeuritis multiplex, a complication of open-heart surgery. J Thorac Cardiov Surg 1975; 69: 816-9.

13 Honet JC, Raikes JA, Kantrowitz A, Pursel SE, Rubenfire M. Neuropathy in upper extremity after open-heart surgery. Arch Phys Med Rehabil 1976; 57:264-7.

14 Aguilar MJ, Gerbode F, Hill J. Neuropathologic complications of cardiac surgery. J Thorac Cardiov Surg 1971; 61:676-85.

15 Branthwaite MA. Cerebral blood flow and metabolism during open-heart surgery. Thorax 1974; 29:633-38.

16 Brierley JB. Neuropathological findings in patients dying after open-heart surgery. Thorax 1963; 18:291-304.

17 Bass RM, Longmore DB. Cerebral damage during open-heart surgery. Nature 1969; 222: 30-33.

18 Brennan RW, Pattersın RH, Kessler J. Cerebral blood flow and metabolism during cardiopulmonary bypass. Neurology (Minneap) 1971; 21:655-72.

19 Carlson RG, Landé AJ, Laıldis B, Rogoz B, Baxter J, Patterson RH, Stenzel K, Lillehei CW. The Landé-Edwards membrane oxygenator during heart surgery. J Thorac Carciov Surg 1973; 66:894-905.

20 Helmsworth JA, Gall EA, Perrin EV, Braley SA, Flege JB, Kaplan S, Keirle AM. Occurrence of emboli during perfusion with an oxygenator pump. Surg 1963; 53:177-85.

21 Brunon AM, Setiey A, Courjon J. Cerebral arterial embolism during extracorporeal circulation. Ann Anesthiol Fr 1977; 18:111-7.

22 Gallagher EG, Pearson DT. Ultrasonic identification of sources of gaseous microemboli during open-heart surgery. Thorax 1973; 28:295-305.

23 Hill JD, Osborn JJ, Swank RL, Aguilar MJ, de Lanerolle P, Gerbode F. Experience using a new Dacron wool filter during extracorporeal circulation. Arch Surg 1970; 101:649-52.

24 Björk VO, Hultquist G. Brain damage in children after deep hypothermia for open-heart surgery. Thorax 1960; 15:284-91.

25 Salerno TA, Lince DP, White DN, Lynn RB, Charette EJP. Monitoring of electroencephalo- gram during open-heart surgery. $J$ Thorac Cardiov Surg 1978; 76:97-101.

26 Wright G, Sanderson JM. Brain damage and mortality in dogs following pulsatile and nonpulsatile blood flows in extracorporeal circulation. Thorax 1972; 27:738-49.

27 Vise WM, Schuier F, Hossman K-A, Takagi S, Zülch KJ. Cerebral microembolization. Arch Neurol (Chicago) 1977; 34:660-5.

28 Bedford PD. Adverse effects of anaesthesia on old people. Lancet 1955 ; 2:259-61.

29 Witoszka MM, Tamura H, Indeglia R, Hopkins RW, Simeone FA. Electroencephalographic changes and cerebral complications in openheart surgery. J Thorac Cardiov Surg 1973; 66: 855-64.

30 Stockard JJ, Bickford RG, Myers RR, Aung MH, Dilley RB, Schauble JF. Hypotension induced changes in cerebral function during openheart surgery. Stroke 1974; 5:730-46.

31 Stockard JJ, Bickford RG, Schauble JF. Pressure-dependent cerebral ischaemia during cardiopulmonary bypass. Neurology (Minneap) 1973; 23:521-9.

32 Harper AM, Glass HI. Effects of alterations in the arterial carbon dioxide tension on the blood flow through the cerebral cortex at normal and low arterial pressures. J Neurol, Neurosurg Psychiatry 1965; 28:449-52.

33 Meyer JS, Gilroy J. Regulation and adjustment of the cerebral circulation. Diseases of the chest 1968; 53:30-6.

34 Milner B. Interhemispheric differences and psychological processes. Br Med Bull 1971; 27:272-7.

35 Kimura D. The asymmetry of the human brain. Sci Am 1973; 228:70-8.

36 Busse EW, Obrist WD. Significance of focal electroencephalographic changes in the elderly. Postgrad Med 1963; 34:179-82.

37 Butler SR, Glass A. Asymmetries in the electroencephalogram associated with cerebral dominance. Electroencephalogr Clin Neurophysiol 1974; 36:481-91.

38 Meyer JS, Gotoh F, Tazaki Y. Circulation and metabolism following experimental cerebral embolism. J Neuropathol Exp Neurol 1962; 21: 4-24.

39 Håkansson $\mathrm{CH}$, Lindgren $\mathrm{M}$, Sulg IA EEG effects of postoperative irradiation treatment of brain tumours. Acta Radiol Ther 1969; 8:301-10. 